\title{
UNA APROXIMACIÓN A LO DEMONÍACO Y LA VIOLENCIA EN EL ESTADIO ÉTICO KIERKEGAARDIANO
}

\author{
José Luis Evangelista Ávila \\ Universidad Autónoma de Chihuahua, México
}

\section{Resumen}

La subjetividad demoníaca atraviesa la obra kierkegaardiana. Su abordaje principal es a través del estadio religioso en el que surge de forma eminente, así como de algunas notas del estadio estético en que también se expresa. En el presente trabajo se busca abonar a la posibilidad de considerar lo demoníaco en el estadio ético y la manera en que puede desembocar en la violencia.

Palabras clave: Subjetividad demoníaca, estadio ético, violencia.

\section{Abstract}

Demonic subjectivity is a topic present through Kierkegaard's works. Its main treatment is given in the religious stage, in which it appears eminently; it is also expressed in some of the aesthetic stage notes. The present work aims to study the possibility of considering the demonic in the ethical stage and how it can lead to violence.

Key words: Demonic subjectivity, ethical stage, violence.

...Uno puede ver cuán insidioso y bábil es el individuo demoniaco cuando usa precisamente aquello que lo salva para progresar en su proyecto demoníaco de evadir lo que lo salva ${ }^{1}$.

El Traficante de modas, comensal en In vino veritas, posee dos características que sirven de introducción al presente. Una es su caracterización en lo

Recibido: 18 de octubre de 2017; Aceptado: 6 de febrero de 2018.

${ }^{1}$ Ronald L. Hall, "Language and Freedom: Kierkegaard's Analysis of the Demonic in The Concept of Anxiety", en International Kierkegaard Commentary. The Concept of Anxiety, ed. por Robert L. Perkins, Macon, Georgia: Mercer University Press, 1984, p. 164. Traducción propia. 
demoníaco del estadio estético ${ }^{2}$; otra, su capacidad para manipular lo más propio de la existencia estética, según plantea al final de su discurso al señalar cómo un comentario suyo basta para cancelar una boda en el último momento y su intención de lograr que toda mujer lleve un anillo en la nariz ${ }^{3}$. Al influir en la inclinación y deseo, el Traficante de modas se declara capaz de manipular lo más propio del esteta.

Este exordio no es casual. Nos brinda una primera aproximación a lo demoníaco y dota de un acceso al propósito de este trabajo que consiste en proponer una lectura de lo demoníaco en el estadio ético. Sin ser la única posible, esta lectura intenta desembocar en un vínculo de estas subjetividades con la violencia. Para lograrlo, planteamos tres partes: 1) una breve revisión de lo demoníaco, 2) abordar una lectura de lo demoníaco en el estadio ético y, 3), señalar vínculos con la violencia.

Tres delimitaciones previas que proseguir: 1) Las restricciones para presentar definiciones ${ }^{4}, 2$ ) la aproximación a los conceptos será según sus efectos sobre la existencia; y, 3) lo ético demoníaco surgirá principalmente de interpretarlo a través de lo estético y lo religioso, pues poco abona desde el interior de sí. Suponemos entonces una compatibilidad en lo demoníaco estético y religioso con lo ético, así como paralelismos entre las subjetividades demoníacas pese a que las expresiones de cada estadio sean propias ${ }^{5}$.

\section{La subjetividad demoníaca. Un acercamiento}

La permanencia en el pecado, su progresión y el reconocimiento de la no-verdad, incluso si se niegan, son pautas supuestas por lo demoníaco, pero no se limita a tales. Para Anti Climacus, el pecado sólo puede abordarse en

2 Para Johannes Climacus: "El comerciante de modas es la desesperación demoníaca apasionada" (Søren Kierkegaard, Postscriptum no científico y definitivo a las Migajas filosóficas, trad. de Javier Teira y Nekane Legarreta, Salamanca: Sígueme, 2010, p. 296 / SKS 7, 271).

${ }^{3}$ Cfr. Søren Kierkegaard, In vino veritas, trad. de Demetrio Gutiérrez Rivera, Madrid: Alianza, 2009, p. 136 y 140 / SKS 6, 68-69 y 70.

4 Vigilus Haufniensis advirtió: "respecto de los conceptos existenciales siempre denota buen tacto el abstenerse de las definiciones" (Søren Kierkegaard, El concepto de la angustia, trad. de Demetrio Gutiérrez Rivera, Madrid: Alianza, 2008, p. 256 / SKS 4, 447).

5 Señaló el seudónimo A: "reproducir un estadio distinto no significa simplemente alcanzarlo, sino alcanzarlo conservando dentro de sí todos los componentes de los estadios precedentes" (Søren Kierkegaard, O lo uno o lo otro 2/1. Un fragmento de vida I, trad. de Begonya Saez Tajafuerce y Darío González, Madrid: Trotta, 2006, 218 / SKS 201). 
el cristianismo ya que en otros espacios tiende a su anulación ${ }^{6}$. Atravesemos, así sea de manera sucinta, algunos rasgos del pecado que nos permitan acceder a la subjetividad demoníaca.

Para Johannes Climacus la existencia es una toma de distancia de la verdad y permanencia en la "no-verdad" que el sujeto debe reconocer y apropiarse $e^{7}$. Para el seudónimo, y parece válido extenderlo al pensamiento del danés, la apropiación subjetiva de una cuestión en apariencia epistemológica (no conocer la verdad) deviene la constatación de la condición propia (ser la no-verdad) y, ésta, en un acto ético que posiciona al individuo en una respuesta y actitud ante una verdad irreductible a un dato de la consciencia, se trata de una relación subjetiva. La existencia se alza en polémica con la verdad", por ello afirma: “¿Cómo podríamos llamar a ese estado de ser la no-verdad y serlo por culpa propia? Llamémosle pecado" 9 .

Al transitar a la (segunda) ética ${ }^{10}$, Kierkegaard supone a la dogmática y, con ella, al otro, cuyo olvido define a la tradición filosófica ${ }^{11}$, sin estos supuestos toda aproximación resulta insuficiente para comprender el pecado ${ }^{12}$. El

${ }^{6} \mathrm{Cfr}$. Søren Kierkegaard, La enfermedad mortal, trad. de Demetrio Gutiérrez Rivera, Madrid: Trotta, 2008, p. 171.

${ }^{7}$ Escribió Climacus: "Quien busca ha de ser concebido como fuera de la verdad (no yendo hacia ella igual que un prosélito, sino huyendo de ella) o como no-verdad. Él es la no-verdad" (Søren Kierkegaard, Migajas filosóficas o un poco de filosofía, trad. de Rafael Larrañeta, Madrid: Trotta, 2004, p. 30 / SKS 4, 222); y, "la propia no-verdad únicamente puedo descubrirla por mí mismo y, sólo al descubrirla yo, queda descubierta, aun cuando todo el mundo lo supiera" (Ibíd., p. 31 / SKS 4, 223). Aquí y en otros casos, las cursivas provienen del original).

${ }^{8}$ Cfr. Ibíd., p. 32 / SKS 4, 224.

${ }^{8}$ Ídem.

${ }^{10}$ Para lo relativo a la segunda ética, sea considerado el trabajo de Arne Grøn "Ética de la repetición”, Enrahonar, no. 29, 1998, pp. 35-45.

${ }^{11}$ Kierkegaard precisó: “«el prójimo» es lo que los pensadores llamarían lo otro, aquello en lo que ha de verificarse lo egoísta del amor de sí. En vista de lo cual, si por los pensadores fuera, no sería necesario siquiera que existiera el prójimo" (Søren Kierkegaard, Las obras del amor, trad. de Demetrio Gutiérrez Rivera, revisado y actualizado por Victoria Alonso, Salamanca: Sígueme, 2006, p. 40).

${ }^{12}$ Anti Climacus cuestiona con intenciones retóricas: ¿qué categoría le falta a Sócrates [y con él a la tradición filosófica] en su definición del pecado? Le falta la categoría de la voluntad, del desafío. La intelectualidad griega era demasiado feliz, demasiado ingenua, demasiado estética, demasiado irónica, demasiado ingeniosa -en una palabra, demasiado pecadora en cierto sentido- como para que le entrase en la cabeza que alguien dejara de hacer el bien a sabiendas, o que a sabiendas de lo que era justo cometiese una injusticia. El helenismo establece un imperativo categórico intelectual (Kierkegaard, La enfermedad mortal, p. 118 / SKS 11, 203). 
pecado, como el mal, encalla en la finitud ${ }^{13}$, no obstante, va más allá por la vía de su progresión, desafío, voluntad y obstinación que lo ubican como un posicionarse ante Dios ${ }^{14}$. Al desafío a lo divino, el sujeto desafía al espíritu ${ }^{15}$, por lo que la respuesta a sí mismo y al prójimo queda comprometida por un ensimismamiento que es autoclausura. La condición humana es puesta contra sí misma.

La autoclausura vincula el mal, el pecado y lo demoníaco. En la autoclausura como expresión de lo demoníaco coinciden El concepto de la angustia y La enfermedad mortal. Haufniensis indicó:

De ordinario, se suele emplear acerca del mal una expresión más metafísica, diciendo que es lo negativo; la expresión ética de lo mismo es justamente la de clausura, sobre todo si se atiende a los efectos del mal en el individuo. Porque lo demoníaco (...) se encierra sólo (SIC); y en esto consiste la profundidad peculiar de la existencia, a saber, en que la propia esclavitud se haga a sí misma prisionera. La libertad es siempre comunicativa (...). La no-libertad, por el contrario, se encierra cada vez más dentro de sí misma y no desea tener ninguna comunicación ${ }^{16}$.

Por su parte, Anti Climacus signó lo demoníaco en el afán desesperado de ser sí mismo ${ }^{17}$, no obstante toda desesperación surja de un no querer ser sí mismo ${ }^{18}$. Una de cuyas vías es la sujeción a una idea con temor de ser separado de ella, por lo que el sujeto huye de la eternidad que podría sacarlo del enclaustramiento donde encuentra su poder, pero también su

13 Pueden consultarse los análisis de Andrés Torres Queiruga en Repensar el mal. De la ponerología a la teología (Madrid: Trotta, 2011), así como los Ensayos de teodicea de Leibniz en que se basa.

${ }^{14}$ Esto lo indicó Anti Climacus en el apartado "El pecado no es una negación sino una posición", de La enfermedad mortal.

${ }^{15}$ Cfr. Kierkegaard, La enfermedad mortal "Libro Primero. Capítulo I".

${ }^{16}$ Kierkegaard, El concepto de la angustia, pp. 219-220 / SKS 4, 425.

17 Para el seudónimo: cuanto mayor sea la conciencia que hay en este yo pasivo que desesperadamente quiere ser sí mismo, tanto mayor será también la potencia de la desesperación, hasta que termine convirtiéndose en algo demoníaco. Su respectivo origen es a buen seguro el siguiente. Un yo, que desesperadamente quiere ser sí mismo, está gimiendo bajo alguna que otra calamidad dolorosa, hasta que al fin es ya imposible eliminarla o separarla de su yo concreto. Nuestro hombre arrojará cabalmente todo el fuego de su pasión sobre este tormento, que al fin no será más que una furia diabólica. Y así, todo está definitivamente perdido (Søren Kierkegaard, La enfermedad mortal, p. 97 / SKS 11, 185).

${ }^{18}$ Cfr. Kierkegaard, La enfermedad mortal, p. 41 / SKS 11, 225. 
miseria ${ }^{19}$. En esta búsqueda desesperada, obstinada y desafiante, "tampoco quiere simplemente por obstinación soltar su propio yo del poder que lo fundamenta, sino que haciendo hincapié en la obstinación quiere imponérsele, desafiándolo y permaneciendo vinculado a Él en fuerza de malicia" 20 . Lo demoníaco supera el pecado.

En su desesperación, la subjetividad demoníaca teme perder la totalidad que genera ${ }^{21}$ y al modo del borracho: "no deja de estarlo ni siquiera un día por miedo a la parada brusca y a la flojedad que ello traería consigo" 22 . En el aprisionamiento, lo demoníaco encuentra su fuerza para afirmar su alejamiento de la verdad/bien ${ }^{23} \mathrm{y}$, habiendo desesperado del arrepentimiento, se angustia ante el bien que concibe amenazante pues teme que la eternidad le arrebate su idea de ser sí mismo.

Para Haufniensis lo demoníaco "sólo aparece debidamente cuando es acosado por el bien, el cual se le acerca por fuera de su límite" 24 . El bien y las expresiones de salvación son las categorías de la libertad, relación, continuidad y apertura que constituyen la comunicación, por lo que aparece ya lo que desarrollará La enfermedad mortal respecto a la búsqueda de clausura ${ }^{25}$. Hay una relación entre la apertura y lo demoníaco que Haufniensis hace explícita: "el criterio decisivo sobre si el fenómeno es o no es demoníaco nos lo dará la posición que el individuo mantenga respecto de la apertura" 26 .

Consecuencia de lo anterior son la "completa abstracción de la continuidad" 27 con lo que "nos evoca la idea del vacío y de la aterradora

${ }^{19}$ Cfr. Idem / SKS 11, 186, donde indica: "Esta idea fija le llega a dominar de tal manera que al fin tiene miedo de la eternidad por una razón muy peculiar, a saber, la de que la eternidad no le vaya a arrebatar esa ventaja infinita [... L]o que más le saca de quicio a nuestro hombre es la idea de que a la eternidad se le ocurriese sacarlo de su miseria".

${ }^{20}$ Ibíd., p. 99 / SKS 11, 187.

${ }^{21}$ Cfr. Ibíd., p. 140 / SKS 11219.

${ }^{22}$ Ibíd., p. 139 / SKS 11, 220.

${ }^{23}$ Cfr. Ibíd., p. 142 / SKS 11, 221.

${ }^{24}$ Kierkegaard, El concepto de la angustia, pp. 211-212 / SKS 4, 421.

${ }^{25}$ Otras expresiones sobre la angustia ante el bien son: "no-libertad que quiere clausurarse en sí misma" (Ibíd., p. 218 / SKS 4, 424), "no desea tener ninguna comunicación [pues] el ensimismamiento es cabalmente mutismo; el lenguaje y la palabra son, en cambio, lo salvador, lo que redime de la vacía abstracción del ensimismamiento" (Ibíd., p. 220 / SKS 4, 425-426), "es reserva cerrada" (Ibíd., p. 224 / SKS 4, 427), cuya representación vendrá dada por "la vacuidad y el aburrimiento" (Ibíd., p. 236 / SKS 4, 434).

${ }^{26}$ Ibíd., p. 227 / SKS 4, 429-430.

${ }^{27}$ Ibíd., p. 233 / SKS 4, 433. Hay que recordar aquí las palabras del Juez Wilhelm quien ha sentenciado respecto al mal al indicar que "la esencia del mal no consiste en tener 
falta de contenido del mal" ${ }^{28}$ que derivarán en la trivialidad de su continente pese a la fastuosidad de sus actos o de las consecuencias de estos ${ }^{29}$.

Recapitulando, las principales determinaciones de lo demoníaco son la angustia ante el bien y el no querer ser sí mismo en tanto posición desafiante. En ambos casos hay una oposición a que el individuo asuma su condición espiritual, de modo que la subjetividad queda suspendida en la reducción a una idea, clausurada, evitando aquello que pudiese modificar el constructo que ha hecho de sí misma para afirmarse desvinculada del espíritu y del poder que la fundamenta. Al negar la condición de espíritu la subjetividad se niega a sí misma y a la revelación, intentando afirmarse en la verdad y el bien que produce idealmente por oposición a la no-verdad y el pecado propios. Teme entonces a la revelación de la que se escandaliza. Esto genera mutismo ${ }^{30} \mathrm{y}$, angustiado del bien fuera de sí, pretenderá mediante imperativos intelectuales el autoconvencimiento de encontrarse en el bien, incluso de una superioridad moral al considerarse como mejor ${ }^{31}$.

En lo demoníaco, cual serpiente Uróboros, el espíritu intenta devorarse a sí mismo adquiriendo fuerzas de este alimento para proseguir en su ambición de eliminar lo que le resulta más propio. En angustia y desesperación se impide la temporalidad y la libertad necesarias para morir. Sin eternidad, sino con una súbita sucesión de momentos sin continuidad, la subjetividad queda encallada en la esclavitud de esta subitaneidad. "Tal esclavitud -escribió Haufniensis- siempre entraña una relación, que nunca deja de existir por más que aparentemente haya desaparecido por completo" 32 .

Los rasgos previos no agotan la subjetividad demoníaca, sin embargo, resultan representativos y nos permiten el avance a considerar sus manifestaciones en el estadio ético, teniendo en mente lo que sucede con el

continuidad" (Kierkegaard, O lo uno o lo otro II. Un fragmento de vida II, trad. de Darío González, Madrid: Trotta, 2007, p. 45 / SKS 3, 48).

${ }^{28}$ Kierkegaard, El concepto de la angustia, p. 234 / SKS 4, 434.

${ }^{29}$ Vigilius Haufniensis intitula uno de los apartados de su trabajo como "Lo demoníaco es vacuidad y aburrimiento" (Kierkegaard, El concepto de la angustia, p. 234 / SKS 4, 433).

${ }^{30}$ De ahí "aquel individuo demoniaco fue poseído por un espíritu mudo" (Søren Kierkegaard, Ejercitación del cristianismo, trad. de Demetrio Gutiérrez Rivera, Madrid: Trotta, 2009, p. 44 / SKS 12, 32).

${ }^{31}$ Cfr. Søren Kierkegaard, La repetición, trad. de Demetrio Gutiérrez Rivera, Madrid: Alianza, 2009, p. 180 / SKS 4, 75.

32 Kierkegaard, El concepto de la angustia, p. 218 / SKS 4, 424. 
amor y sus efectos, es decir, que si bien surgidos ante Dios, han de hacerse palpables en la relación con el prójimo.

\section{Lo demoníaco en la subjetividad ética}

Las referencias a lo demoníaco en la obra kierkegaardiana, centradas en lo religioso y ocasionalmente en lo estético, son limitadas en lo relativo a lo ético. En las líneas siguientes se pretende una interpretación que permita una aproximación, posible entre otras, que abone a ese espacio de reflexión.

Al abordaje de la relación entre lo demoníaco y lo ético se suma la dificultad planteada por la asociación del segundo con los aspectos moralmente aceptables cuando con propiedad se vincula a los constructos que una época y contexto establecen. Que lo ético se identifica con planteamientos específicos válidos a partir de una racionalidad y circunstancias espacio-temporales determinadas, cobra evidencia en las prácticas de otros contextos que nos resultan aberrantes, sin embargo sean comunes en sus marcos de referencia. Al identificar el estadio ético con "el bien", opera el mismo yerro que iguala al esteta con el hedonista y al religioso con una piedad moralista.

Otra dificultad surge de las descripciones que los seudónimos éticos hacen de sí mismos, pues al excluir aquello que no se ajusta a lo general, sus referencias a lo demoníaco son exógenas y lo sitúan en lo estético o lo religioso. Por otra parte, dado lo general, si se presenta al interior de lo establecido, será incorporado bajo otras categorías. Según lo anterior, la presencia de lo demoníaco en el estadio ético ha de ser inferida.

Este abordaje también supone la comprensión del estadio ético a través de su relación con lo general, según se plantea en Temor y temblor y la insinuación de su constitución como una pauta variable en función de la validación que de ello hace el contexto en que se integra ${ }^{33}$. De ser válido lo anterior, puede derivarse que lo general dota de un sostén que imposibilita al estadio ético para considerarse en lo demoníaco pues, mediante

${ }^{33}$ Si bien lo ético puede ser comprendido como la esfera de la existencia y como ciencia (cfr. Azucena Palavicini Sánchez, "Ethicism”, en Kierkegaard's Concepts. Tome III: Envy to Incognito, ed. por Steven M. Emmanuel, William McDonald y Jon Stewart, Reino Unido: Ashgate, 2014, pp. 21-27), hay que precisar el vínculo que guarda el deber y la elección de la primera con los contenidos venidos de la segunda, por lo que entre ambas pautas hay un vínculo profundo. 
"atenuaciones culpables" 34 , plantearían un marco de comprensión válido que disimularía el desafío y sus otras condiciones. De este modo, se trae a la luz la imposibilidad de lo ético para comprender lo demoníaco en su estadio y su silencio al respecto.

Tras sortear la poca o nula referencia que plantean las subjetividades éticas hacia lo demoníaco en su estadio, debe evitarse el malentendido que al vincular lo ético a lo general pareciera plantear que la condición de lo demoníaco atraviesa de un sujeto a otro o ser la condición de una época, aspecto incompatible con la individualidad del pecado ${ }^{35}$ y la espiritualidad del individuo kierkegaardiano.

Señalemos algunas notas sobre el estadio ético. "La esfera ética de la existencia se caracteriza por la relación del individuo con el deber" ${ }^{36}$, una de cuyas expresiones es la elección ${ }^{37}$. Para el Juez Wilhelm, en la elección surge lo ético y, con ello, la personalidad ${ }^{38}$. Lo elegido involucra su validación a través de las normas y el deber dados, es decir, lo general. El sujeto ético se elige en lo general, de ahí que el Juez Wilhelm sea lo que se esperaría de un sujeto ético en su contexto: esposo, padre, amigo y funcionario del Estado. Al elegirse en el deber, el ético se elige en lo general que sostiene el deber, de ahí que la comprensión de la subjetividad ética atraviese por lo general.

Retornemos al Traficante de modas para subsanar la aparente imposibilidad de vincular lo demoníaco con lo general. El comensal del banquete no abordó la manipulación directa de su clientela sino su control a través de la moda, al trasladar esto a lo ético, los sujetos proceden por sí mismos en la elección del deber, con lo que guardan su individualidad, sin embargo, el deber guarda la posibilidad de ser atravesado por lo demoníaco. No se trata de que la tienda de lo general imponga la venta a su clientela, sino de que la oferta puede presentarse como el mejor (y único) producto.

${ }^{34}$ Kierkegaard, La enfermedad mortal, p. 124 / SKS 11, 207.

35 "La categoría del pecado es la categoría de la individualidad". (Kierkegaard, La enfermedad mortal, p. 153 / SKS 11, 230).

${ }^{36}$ Palavicini Sánchez, "Ethicism”, p. 22. Traducción propia.

${ }^{37}$ En la entrada "Choise" (Gerhard Thonhauser, en Kierkegaard's Concepts. Tome I: Absolute to Church, ed. por Steven M. Emmanuel, William McDonald y Jon Stewart, Reino Unido: Ashgate, 2013, pp. 193-199) puede leerse “cada elección es esencialmente ética" (p. 194, traducción propia) o, en el Juez Wilhelm, "lo ético es propiamente lo que hace que la elección sea una elección” (Kierkegaard, O lo uno o lo otro II, 158 / SKS 5, 165).

${ }^{38}$ Cfr. Kierkegaard, "El equilibrio entre lo estético y lo ético en la formación de la personalidad”, pp. 154 y ss. / SKS 3, 160 y ss. 
Súmese que las notas de lo demoníaco resultarían atenuadas por el cobijo de lo general.

El Juez Wilhelm aparece como el seudónimo más acabado de lo ético, pero a él han de agregarse como exponentes ejemplares los héroes trágicos de Temor y temblor. Al atender a las acciones del Juez y los héroes trágicos (Agamenón, Bruto y Jefté), los personajes parecen separarse, no obstante, al considerarlos desde lo general expresan su cercanía: todos representan ideales y figuras que cumplen lo esperado por lo general en su contexto. Por ello, también Agamenón es un "arquetipo ético"39.

Si lo demoníaco encuentra arraigo en lo ético, sucederá como con la desesperación o la angustia que al hacerse evidentes revelarán que siempre han estado ahí. En el caso de la existencia ética las formas de ocultamiento de lo demoníaco son numerosas, precisamente, por el solapamiento de lo general. El estadio ético brindará héroes mientras compartamos sus marcos de comprensión, sin embargo, serán cuestionados cuando haya un cambio en "lo general". Es la generalidad aceptada la que permite la cotidianidad de lo que causaría estupor en otros contextos.

Cuando lo demoníaco se aproxima a lo ético, despierta persecución y crueldad en su contra ${ }^{40} \mathrm{y}$, aunque poco se dice sobre lo demoníaco en el estadio ético, hay un señalamiento importante de Haufniensis: "acaso nunca haya estado lo demoníaco tan extendido como en nuestros tiempos. ¡Sólo que en la actualidad aparece especialmente en las esferas espirituales!" ${ }^{41}$. Estas "esferas espirituales" parecen ser aquellas que ironiza Kierkegaard en La época presente al enjuiciar a su época como "esencialmente sensata, reflexiva, desapasionada, encendiéndose en fugaz entusiasmo e ingeniosamente descansando en la indolencia" ${ }^{42}$, donde incluso lo espiritual se encuentra mediado por lo general.

Retornemos al Juez Wilhelm. Su permanencia como figura del estadio o esfera ética nos revela la permanencia de ciertos valores hasta el presente, sin embargo, un cambio en lo general nos hace difícil el reconocimiento de estas figuras. Las sociedades de pervertidos descritas por Sade, Severino/ Gregorio de La Venus de las pieles o incluso Saló o los 120 días de Sodoma

${ }^{39}$ Expresión de Laura Liva en la entrada "Agamemnon: From Ancient Hero to Modern Ethical Archetype" (Kierkegaard's Literary Figures and Motifs. Tome I: Agamemnon to Guadalquivir, ed. por Katalin Nun y Jon Stewart, Reino Unido: Ashgate, 2014, p. 1).

${ }^{40}$ Kierkegaard, El concepto de la angustia, p. 214 / SKS 4, 422.

${ }^{41}$ Ibíd., p. 239 / SKS 4, 436-437.

${ }^{42}$ Søren Kierkegaard, La época presente, trad. de Manfred Svensson, Madrid: Trotta, 2012, p. 41 / SKS 8, 65. 
de Pasolini, son ejemplos donde intenta imponerse una generalidad, inversa a la que conocemos, pero que con propiedad formaría parte de otra forma de lo ético. Su tendencia estética y violenta, pese a su impresión, es secundaria. En el caso de Juliette, por dar cuenta de uno de ellos, se intenta la mediación de lo general y la estructura de la obra presenta una razón que se expande dictando preceptos, prácticas y adoctrinamiento para derrumbar los prejuicios, sentimientos inadecuados o razonamientos débiles, lo que permitirá un desarrollo más apropiado de la propia naturaleza en la búsqueda de los fines y objetivos que le son propios. Sin el señalamiento de los contenidos que ruborizarían a más de uno, la obra podría considerarse una composición que pretende construirse como lo general.

Así como el esteta se metamorfosea entre deseos y placeres inmediatos con los que busca fundirse, en el estadio ético el sujeto pretende interiorizar lo general al convertirlo en la idealidad con la que media su subjetividad. En ambos casos la identidad sólo se logra en momentos aislados, por lo que lo ético se encuentra imposibilitado de dar cuenta constantemente de lo general en sí mismo, no obstante, permite nulificar los extremos representados por las subjetividades estéticas y religiosas al tender a una nivelación ${ }^{43}$ donde las subjetividades encuentran "su $\tau \dot{\varepsilon} \lambda$ os en lo general, [y] su tarea ética consiste en expresarse constantemente en ello, despojándose de su carácter individual para convertirse en lo general" ${ }^{44}$. La subjetividad puede comprenderse entonces por la abstracción, de modo que los individuos han de ser referidos a lo general en que se eligen, que los representa y al que representan. Ahora bien, si lo general plantea atributos de lo demoníaco, la subjetividad que se identifique con ello elegirá lo demoníaco para sí.

${ }^{43}$ De este concepto, Kierkegaard indica en La época presente: La nivelación no es obra de un individuo, sino un juego de reflexión en manos de un poder abstracto. (...) el individuo que nivela a otros también es arrastrado, y así sucesivamente. Mientras que el individuo, de manera egoísta, sostiene saber lo que está haciendo, es justo decir que ninguno sabe lo que está haciendo. (...) como la unanimidad en entusiasmo resulta en algo más que no es del individuo, así también un algo más emerge aquí. Se levanta un demonio que ningún individuo puede controlar. Y si bien el individuo en forma egoísta disfruta de la abstracción en el breve instante de la nivelación, así está firmando el decreto de su propia perdición. (...) el triunfo de la nivelación es eo ipso su perdición. Ningún período, ninguna época, y por tanto tampoco la época presente, puede detener el escepticismo de la nivelación, porque en el mismo momento del intento, volverá a mostrar cuál es su ley. Solo puede ser detenida cuando el individuo, en forma individual, conquista la intrepidez de lo religioso (p. 62 / SKS 8, 83).

${ }^{44}$ Søren Kierkegaard, Temor y temblor, p. 639 / SKS 4, 148. 
Las categorías que hemos puesto de relieve para lo demoníaco son las venidas del pecado (no-verdad, desafío, posicionamiento y conciencia de estar delante de Dios), la angustia ante el bien y el no querer ser sí mismo, mismas que generan clausura, mutismo, ensimismamiento, lo súbito y negación del espíritu.

La clausura, como desviación de la condición espiritual, coincide con la afirmación de Leo Stan, sobre el pecado en Kierkegaard como un "viciarse de las facultades humanas" que afecta "las relaciones con lo divino, el mundo y con los otros" ${ }^{45}$. Partamos "[d]el silencio [que] puede ser divino o demoníaco" 46 según la relación que guarde con la interioridad y la comunicabilidad.

El silencio vinculado a lo demoníaco involucra ensimismamiento y mutismo, sin embargo, estos no se identifican necesariamente con la ausencia de sonido sino con la incomunicabilidad. Tres rasgos de incomunicabilidad dados por los seudónimos abonan a esta postura. El primero lo brinda A cuando afirma que "la música es lo demoníaco" ${ }^{47}$; el segundo proviene de Johannes Climacus al poner en entredicho la comunicación en la reminiscencia, pues la "comunicación" se convierte en una actualización de lo que ya posee el sujeto y se tornaría, junto con el maestro, "algo contingente, insignificante" ${ }^{48}$. Sin comunicación queda la reminiscencia y, el sujeto, antes que a la comunicación deberá servirse del entendimiento propio como sucede en el ideal ilustrado.

La tercera descripción del silencio en el sonido proviene de Johannes de Silentio quien lo describe en relación con Abraham: "si, hablando, no puedo hacerme comprender, entonces de hecho no hablo, aunque perore

${ }^{45}$ Leo Stan, “Sin”, en Kierkegaard's Concepts. Tome VI: Salvation to Writing, ed. por Steven M. Emmanuel, William McDonald y Jon Stewart, Reino Unido: Ashgate, 2015, p. 45. Traducción propia. Respecto a lo demoniaco, Stephen N. Dunning indica se trata de una "perversión de la interioridad" ("Kierkegaard's Systematic Analysis of Anxiety", en International Kierkegaard Commentary. The Concept of Anxiety, ed. por Robert L. Perkins, Macon, Georgia: Mercer University Press, 1984, p. 27. Traducción propia).

${ }^{46}$ Robert C. Roberts, "The Socratic Knowledge of God", en International Kierkegaard Commentary. The Concept of Anxiety, ed. por Robert L. Perkins, Macon, Georgia: Mercer University Press, 1984, p. 149. Traducción propia. También Hall en "Language and Freedom: Kierkegaard's Analysis of the Demonic in The Concept of Anxiety" indica que "el lenguaje es el factor decisivo para distinguir la vida de la fe de la vida demoníaca" (p. 154. Traducción propia).

${ }^{47}$ Kierkegaard, O lo uno o lo otro I, p. 88 / SKS 2, 71.

${ }^{48}$ Kierkegaard, Migajas filosóficas, p. 28 / SKS 4, 220. 
sin interrupción un día entero" ${ }^{49}$. En lo ético se da el silencio en la medida en que no hay una expresión de la interioridad sino de lo general, a la que los sujetos pueden llegar por sí mismos y que ni siquiera se expresa como música sino como ruido. De ahí la crítica a la charla, la habladuría y la cháchara donde, pese al aparente diálogo, persiste la incomunicabilidad. En dirección inversa, este ruido evita el silencio, "teme al instante del silencio, que hace evidente el vacío" ${ }^{50}$ o lo tergiversa al ser "un silencio que 'miente' detrás de la expresión libre" 51 . La interioridad promueve el silencio, sea uno real por su exceso en el caso de Abraham o uno falso por su defecto mediante la nivelación. En ambos casos la comunicación es imposible y, junto al jolgorio externo, el espíritu permanece incomunicado. Una interioridad vacía condena al silencio al tiempo que exige habladurías para su distracción.

Lo demoníaco del estadio ético se acompaña del disimulo de la clausura mediante las habladurías y del intento de solapar su obstinación y desafío. Antes que altivo, el sujeto ético se proclamará servidor del deber que ha elegido, sin embargo, no cuestiona en qué medida ese deber se han endiosado para posicionarse frente a Dios. El deber proclamado por lo general se sitúa por encima de toda ética, incluido el mandato divino, y exige sumisión de sus fieles. Ejercitación del cristianismo plantea esta crítica donde lo general, expuesto en la obra como "lo establecido" se autodiviniza y compite con lo divino, pero cuidándose de no hacerlo de forma explícita: "que el orden establecido se haya convertido en algo divino, que sea visto como lo divino, es una falsedad originada con la ayuda del desconocimiento de su propia ascendencia" 52 .

Por la obediencia al ídolo de lo establecido, lo general plantea la posibilidad del desafío obstinado y "da de palabra la razón a Dios, pero cuidándose muy bien de mantener en su fuero interno el convencimiento absoluto de que es él el que en realidad tiene razón"53. Así, el tributo

${ }^{49}$ Kierkegaard, Temor y temblor, p. 712 / SKS 4, 201.

${ }^{50}$ Kierkegaard, La enfermedad mortal, p. 76 / SKS 8, 93.

${ }^{51}$ Hall, "Language and Freedom: Kierkegaard's Analysis of the Demonic in The Concept of Anxiety", pp. 160-161.

52 Søren Kierkegaard, Ejercitación del cristianismo, trad. de Demetrio Gutiérrez Rivero, Madrid: Trotta, 2009, p. 104 / SKS 12, 97. Que lo general se posicione como lo más alto es lo que plantea la disyuntiva en Temor y temblor, pues: "O el individuo puede en cuanto tal relacionarse absolutamente con lo absoluto, y en este caso la ética no es lo supremo, o Abraham está perdido" (Kierkegaard, Temor y temblor, p. 736 / SKS 4, 201).

${ }^{53}$ Søren Kierkegaard, La repetición, p. 180 / SKS 4, 75. Se ha modificado el plural de 
que rinde la subjetividad ética a lo establecido es el obstinado, aunque disimulado, desafío a Dios.

El juez Wilhelm argumenta a favor de la continuidad en lo ético ${ }^{54}$, pero esta continuidad se torna problemática. La historia personal deviene un contenido que ha de rendirse a lo general o pecará y, en la historia universal, la continuidad del sujeto no tiene cabida. La "historia universal" es la aparición súbita de diversos episodios que son considerados relevantes "para la humanidad”. Emergen mímicos como una narrativa visual cuyos episodios aparecen al modo de las imágenes en la Capilla Sixtina o una novela gráfica contemporánea. La continuidad del individuo, si no desaparece a los pies de esta historia, se convierte en enunciados fragmentarios que lo generalizan a través de un cuadro histórico en el que ha depositado su continuidad hasta entonces valorada. La presencia y continuidad de los sujetos en la historia es, en el mejor de los casos, una manifestación súbita entre otras.

Si hay algún valor en la "historia personal" del sujeto ético, éste se encuentra en la decisión, cuando al elegir, se elige, y le convidan de una permanenciaidentitaria con logeneral, no obstantelas elecciones y momentos de elección sean pinceladas selectas en que lo ético se construye a través de lo general donde el tiempo se hace irrelevante ${ }^{55}$. Para lo ético demoníaco la continuidad será como el desarrollo de una ecuación: en apariencia plena en su resultado, no obstante formal y carente de contenidos, por lo que válida para todos permite el reconocimiento de lo general, pero no de los sujetos.

Lo establecido desespera del perdón de los pecados pues, fuera de sí, no hay nada que sea perdonado, ni una ética superior capaz de juzgarlo. Cerrado al perdón, resta la angustia ante el bien que, para Haufniensis, es el distintivo principal de lo demoníaco. En su clausura, lo ético demoníaco se blinda al identificarse con el bien establecido y al rechazar toda exterioridad que no se identifique con lo propio. El pecado, queda fuera de sí, será condenado. Lo general, cual baño lustral, pretende exorcizar la angustia ante el bien. En autoclausura e incomunicabilidad, lo demoníaco se torna súbito y desafiante para concluir desesperado del perdón de los pecados y angustiado por el bien al que rehúye mediante el escándalo, la condena y el trasvestirlo como un mal.

Si la subjetividad ética deviene demoníaca, lo demoníaco estará presente en la elección, sus contenidos y lo general por los cuales la subjetividad se

la versión citada para mantener la concordancia.

${ }^{54}$ Cfr. Kierkegaard, O lo uno o lo otro II, p. 45 / SKS 3, 48.

${ }^{55}$ Kierkegaard, Migajas filosóficas, p. 28 / SKS 4, 220. 
constituye. Al manipular y hacerse de la elección y el deber de lo ético, de la inclinación y el deseo del esteta y de la condición espiritual de lo religioso, la subjetividad demoníaca se apropia de lo más distintivo de la condición humana y de las manifestaciones fundamentales de cada estadio.

\section{De lo ético demoníaco a la violencia}

En Las obras del amor, Kierkegaard se dirige a "aquel Individuo" ${ }^{6}$, su lector, y plantea que es en el prójimo donde ha de confrontarse lo egoísta del amor. Ello abre una dialéctica entre el individuo y el prójimo, no obstante, sus reflexiones suelen dirigirse al primero. Acorde a lo anterior, los efectos de la interioridad desbordan a la subjetividad considerada en sí misma, para relacionarse con Dios y verificarse en el prójimo. Esto abre el cuestionamiento por la concreción de las prácticas individuales en lo social y, si bien el danés aborda una crítica social en su obra, es en menor medida que en relación con el individuo, en el caso de lo ético demoníaco estas referencias son prácticamente nulas.

En lo que resta, se intentará vincular la angustia de lo demoníaco ético ante el bien con su proyección social al remitirla a la violencia como uno de sus efectos, lo que no involucra sea el único. Para esto, se recurrirá a algunas notas del pensamiento de René Girard. En lo individual, la angustia ante el bien genera una actitud desafiante contra lo divino que interpreta como una amenaza externa, mientras que, en su asentamiento en lo general, lo ético confronta y desafía aquello que se encuentra por fuera de lo establecido y es signado como mal o causa de escándalo ${ }^{57}$. Exterioridad irreductible, con independencia de ser bien o mal que, al tratarse del prójimo como un testigo de la verdad, producirá angustia y desencadenará la persecución de la verdad en su contra.

Para Sanfransky, “un ser que dice 'no' y que conoce la experiencia de la nada puede elegir también la aniquilación" ${ }^{8}$. Este ser es quien ha atravesado por la angustia, de modo que la angustia ante el bien abre el desafío contra Dios, pero también posibilita la condena y una violencia contra el prójimo.

${ }^{56}$ Kierkegaard, Las obras del amor, p. 17 / SKS 9, 11.

${ }^{57}$ Cfr. Kierkegaard, Ejercitación del cristianismo, el apartado: "La posibilidad del escándalo que no guarda relación con Cristo en cuanto Cristo (el Dios-hombre), sino con él en cuanto llana y simplemente un hombre individual que entra en colisión con el orden establecido".

${ }^{58}$ Rüdiger Safransky, El mal o el drama de la libertad, trad. de Raúl Gabás, Barcelona: Tusquets, 2000, p. 13. 
Dios y el bien son sustituidos en lo general por el ídolo de lo establecido que, cual Moloch, exige sacrificios constantes para mantener un estado de cosas xenófobo.

La reducción a lo general supone la trasmutación de conceptos, pues ubicándose en lo que ha dictaminado como "bien" (lo establecido) se angustia por el "mal" (la exterioridad), no obstante pueda tratarse de una angustia ante el bien (ante Dios o ante el testigo de la verdad). Lo ajeno, bien o mal, es objeto de persecución que ha de incorporarse o ser eliminado. La violencia será consecuencia de esta movilización.

Aunque de Temor y temblor pueda considerarse violento a Abraham y lo religioso, no puede olvidarse que fueron los héroes trágicos, arquetipos de lo ético, y no el padre de la fe, quienes concluyeron el sacrificio. La revisión de Johannes de Silentio concluye ahí, pero al seguir a Agamenón a través de las tragedias griegas, el héroe será llevado a la muerte por asesinato. Cabe aquí la explicación que brinda René Girard a los casos de Job y Edipo como chivos expiatorios: "El chivo expiatorio es un ídolo roto en mil pedazos. Ascensión y caída están enlazadas", "la 'ruta antigua de los hombres perversos' comienza por la grandeza, la riqueza y el poder, pero concluye con un fulminante desastre" ${ }^{59}$. ¿Podemos abonar algo a esto desde lo ético demoníaco?

Hay algunos paralelismos que nos permiten considerar un vínculo entre la violencia y lo ético demoníaco. En los sacrificios de los héroes trágicos como en los aludidos por Girard hay una primera nota común: son "comprendidos" y enaltecidos por lo general que los respalda en la medida en que el asesinato se convierte en un ritual que dota de cohesión social ${ }^{60}$, mientras que la salida de lo general causa escándalo.

Anti Climacus describe el escándalo en que se condena a quien pareciera considerarse más que dios (la divinización de lo establecido), mientras que Temor y temblor planteó la alternativa dada a dicho pecador: su integración por el arrepentimiento o la condena ${ }^{61}$. Entre la violencia y el agobio señalados por Girard como desencadenantes para la búsqueda de un chivo

${ }^{59}$ René Girard, La ruta antigua de los hombres perversos, trad. de Francisco Díez del Corral, Barcelona: Anagrama, 2002, pp. 24 y 45.

${ }^{60}$ Según Castro Rocha: "La canalización de la violencia contra una única persona propicia el retorno al orden, pues todos se unen para sacrificarla" (Joao Cezar Castro Rocha, ¿Culturas shakespearianas? Teoría mimética y América Latina, México: Cátedra Eusebio Francisco Kino SJ, 2014, p. 57).

${ }^{61}$ Cfr. Kierkegaard, Temor y temblor, p. 369 / SKS 4, 148. 
expiatorio $^{62}$ habría que incorporar el escándalo como una puntualización de ese agobio. Para el autor francés, "el chivo expiatorio es el inocente que polariza sobre él el odio universal" ${ }^{63}$, puede ser el bien o el mal que acosa y contraviene a lo establecido, por lo que al escandalizar desata sobre sí una "venganza divina o intervención punitiva de la divinidad" ${ }^{64}$ que se actualiza a través de lo general ${ }^{65}$. Esta violencia, al afirmar la cohesión social, afirma a lo establecido.

Si lo general produce violencia contra el origen del escándalo, esta puede explicarse en atención a la exposición de Girard, pero también el escándalo y lo demoníaco ético. El posterior asesinato de Agamenón en la tragedia que lleva su nombre resulta ambiguo en lo relativo al apoyo general debido a la reclama del coro, pero mantiene una validación en lo referente a lo más propio del pensamiento trágico, la trasgresión o bybris que la hacen comprensible ante lo general y justifican la violencia que caerá sobre el otrora héroe.

Sin ser el único camino de los héroes, el personaje griego trágico suele dar cuenta de la transición del heroísmo al vituperio. Desde lo general, esto se explica por una paradoja que la posición del héroe forja en el corazón de lo establecido y cuya solución se encontraría en una violencia cíclica que elimina al objeto de escándalo para producir un nuevo héroe. La paradoja del héroe trágico es la siguiente: ¿Cómo puede un héroe ubicarse dentro y por encima de lo general al mismo tiempo? En tanto héroe, es ubicado por lo establecido fuera de lo general (objeto de escándalo) y próximo a desencadenar la censura. Para reintegrarlo se le atribuirá la bybris, arrepentimiento y condena la suponen.

Al héroe ético se le exige permanecer fuera de lo general (en tanto héroe) y dentro (en cuanto héroe ético). Será objeto de escándalo por su distancia de lo general o por su retorno culpable. Habiendo alcanzado el heroísmo, el héroe es convertido en culpable, como sucede en los análisis

${ }^{62}$ René Girard, La violencia y lo sagrado, trad. de Joaquín Jordá, Barcelona: Anagrama, 2012, p. 88.

${ }_{63}$ René Girard, La ruta antigua de los hombres perversos, p. 15.

${ }^{64}$ Ibíd., p. 28.

${ }^{65}$ Girard señala sobre la "Biblia de Jerusalén: su traducción sugiere admirablemente la identidad del dios y la multitud. Dios derriba a los grandes, pero es la multitud quien les pisotea. Dios encadena a las víctimas, pero su intervención es pública, se efectúa en presencia de esa misma multitud que quizá no ha permanecido completamente pasiva" (Ibíd., p. 29). 
girardianos, la violencia desencadenada supone y justifica la existencia de un pecado, así se recurra a uno invisible ${ }^{66}$.

Encontrada (creada) la culpa en el otro, la violencia puede producirse y validarse por lo divino. En el escándalo, la pretensión de ser más que dios (lo establecido) descrito en Ejercitación del cristianismo es la bybris, comprensible y justificada por lo general. El chivo expiatorio está dispuesto y su eliminación supondrá la generación de nuevos héroes. En este punto, como señaló Castro Rocha sobre los mecanismos de violencia en Girard:

El mecanismo del chivo expiatorio se torna más eficiente cuando deja de ser puramente arbitrario, al dejar de ser exclusivamente aleatorio, en el sentido de que se puede o no volver a entrar en acción en el momento de crisis. El mecanismo del chivo expiatorio se convierte en fuerza propiamente civilizadora (...) en el momento en que deja de ser fruto tan solo del azar ${ }^{67}$.

\section{Conclusiones}

Lo establecido permite posibilidades de asociación, angustiadas y desafiantes ante el bien, capaces de imponer "su propio bien" a través de una validación general. En caso de extenderse como lo demoníaco, lo ético guarda la posibilidad de devenir violento si pretende eliminar el origen de su angustia que el otro, ajeno a lo general, representaría. Esto permite a lo ético demoníaco colaborar en la comprensión de diversas formas de violencia sistémica y, con ello, ubicar a Kierkegaard como interlocutor de autores contemporáneos avocados a tales reflexiones y a las maneras en que esto genera subjetividades.

Si bien resulta un anacronismo el imponer al danés conceptos y reflexiones políticas propias de autores los siglos XX y XXI, es preciso reconocer que el recorrido de estos últimos plantea formas de relación entre política y subjetividad, mientras que los análisis kierkegaardianos sobre la subjetividad permanecieron vinculados a su praxis y dimensión religiosa ${ }^{68}$, lo que le aproxima indirectamente a lo político.

${ }^{66}$ Cfr. Girard, La ruta antigua de los hombres perversos.

${ }^{67}$ Castro Rocha, Culturas shakespearianas, p. 62.

68 "Lo que tenía un aspecto político y creía ser político, un día se descubrirá como movimiento religioso" (la traducción, tomada del ensayo "La conjuración sagrada" de Georges Bataille, procede de Kierkegaard, BOA ms.5.26). 
No podemos obviar a Kierkegaard al plantear la consolidación violenta de lo general cuando las subjetividades han quedado englobadas por lo político o lo establecido, es decir, por una ley que pretende absorberlo todo $^{69}$. Bajo el cobijo de lo general la violencia puede considerarse comprensible, conveniente y enaltecida, no obstante consista en el asesinato de sus respectivos hijos o de pueblos enteros en la medida en que se realice acorde al dictamen de lo establecido.

Cuando lo ético se alza como demoníaco y se concreta de forma violenta en la exclusión del otro, esta violencia corre el peligro de normalizarse en la historia y, de la mano de lo establecido, devendrá una imperceptible fuente de héroes. Mientras lo demoníaco de lo estético o lo religioso pueden ser acusados por lo establecido, el peligro de lo ético demoníaco se alza por el silencio que impide su detección pese a la magnitud de los crímenes que oculta.

\section{Bibliografía}

Kierkegaard, Søren, Ejercitación del cristianismo, Madrid: Trotta, 2009.

- El concepto de la angustia, Madrid: Alianza, 2008.

- In vino veritas, Madrid: Alianza, 2009.

_ O lo uno o lo otro 2/1. Un fragmento de vida I, Madrid: Trotta, 2006.

_ O lo uno o lo otro II. Un fragmento de vida II, Madrid: Trotta, 2007.

- Postscriptum no científico y definitivo a las Migajas filosóficas, Salamanca: Sígueme, 2010.

L La enfermedad mortal, Madrid: Trotta, 2008.

_L La época presente, Madrid: Trotta, 2012.

L L L repetición, Madrid: Alianza, 2009.

— Las obras del amor, Salamanca: Sígueme, 2006.

- Migajas filosóficas o un poco de filosofía, Madrid: Trotta, 2004.

Castro Rocha, Joao Cezar, ¿Culturas shakespearianas? Teoría mimética y América Latina, México: Cátedra Eusebio Francisco Kino SJ, 2014.

Girard, René, La violencia y lo sagrado, Barcelona: Anagrama, 2012.

${ }^{69} \mathrm{Cfr}$. La crítica de Giorgio Agamben a la pretensión omnipresente de la ley en Estado de excepción. Homo sacer II, 1. 
_L La ruta antigua de los hombres perversos, Barcelona, Anagrama, 2002.

Grøn, Arne, “Ética de la repetición”, Enrahonar, no. 29, 1998.

Hall, Ronald L., "Language and Freedom: Kierkegaard's Analysis of the Demonic in The Concept of Anxiety", en International Kierkegaard commentary. The Concept of Anxiety, ed. por Robert L. Perkins, Macon, Georgia: Mercer University Press, 1984.

Liva, Laura, "Agamemnon: From Ancient Hero to Modern Ethical Archetype", en Kierkegaard's Literary Figures and Motifs. Tome I: Agamemnon to Guadalquivir, ed. por Katalin Nun y Jon Stewart, Reino Unido: Ashgate, 2014.

Palavicini Sánchez, Azucena, "Ethicsm”, en Kierkegaard's Concepts. Tome III: Envy to Incognito, ed. por Steven M. Emmanuel, William McDonald y Jon Stewart, Reino Unido: Ashgate, 2014.

Roberts, Robert C. “The Socratic Knowledge of God”, en International Kierkegaard Commentary. The Concept of Anxiety, ed. por Robert L. Perkins, Macon, Georgia: Mercer University Press, 1984.

Safransky, Rüdiger, El mal o el drama de la libertad, Barcelona: Tusquets, 2000.

Stan, Leo, "Sin", en Kierkegaard's Concepts. Tome VI: Salvation to Writing, ed. por Steven M. Emmanuel, William McDonald y Jon Stewart, Reino Unido: Ashgate, 2015.

Thonhauser, Gerhard "Choise", en Kierkegaard's Concepts. Tome I: Absolute to Church, ed. por Steven M. Emmanuel, William McDonald y Jon Stewart, Reino Unido: Ashgate, 2013.

Torres Queiruga, Andrés, Repensar el mal. De la ponerología a la teología, Madrid: Trotta, 2011. 